\title{
IR spectral analysis for the diagnostics of crust earthquake precursors
}

\author{
R. M. Umarkhodgaev ${ }^{1}$, V. A. Liperovsky ${ }^{2}$, V. V. Mikhailin $^{1}$, V. V. Bogdanov $^{3}$, C.-V. Meister ${ }^{4}$, and E. V. Liperovskaya ${ }^{2}$ \\ ${ }^{1}$ Institute of Nuclear Physics, Lomonosov State University, Leninskie gory, 119991 Moscow, Russia \\ ${ }^{2}$ Institute of Physics of the Earth of the Russian Academy of Sciences, Bolshaya Gruzinskaya 10, 123995 Moscow, Russia \\ ${ }^{3}$ Institute of Cosmophysical Research and Radio Wave Propagation, Far Eastern Branch of the Russian Academy of Sciences, \\ 684034 Petropavlovsk-Kamchatsky, Russia \\ ${ }^{4}$ Institut für Kernphysik, Technische Universität Darmstadt, Schlossgartenstr. 9, 64289 Darmstadt, Germany
}

Correspondence to: C.-V. Meister (c.v.meister@skmail.ikp.phyik.tu-darmstadt.de)

Received: 21 August 2012 - Accepted: 1 October 2012 - Published: 7 November 2012

\begin{abstract}
Some possible physical processes are analysed that cause, under the condition of additional ionisation in a pre-breakdown electric field, emissions in the infrared (IR) interval. The atmospheric transparency region of the IR spectrum at wavelengths of $7-15 \mu \mathrm{m}$ is taken into account. This transparency region corresponds to spectral lines of small atmospheric constituents like $\mathrm{CH}_{4}, \mathrm{CO}_{2}, \mathrm{~N}_{2} \mathrm{O}, \mathrm{NO}_{2}, \mathrm{NO}$, and $\mathrm{O}_{3}$. The possible intensities of the IR emissions observable in laboratories and in nature are estimated. The acceleration process of the electrons in the pre-breakdown electrical field before its adhesion to the molecules is analyzed. For daytime conditions, modifications of the adsorption spectra of the scattered solar emissions are studied; for nighttime, variations of emission spectra may be used for the analysis.
\end{abstract}

\section{Introduction}

The study of clouds of increased ionization in the Earth's atmosphere continues to be of importance and interest to observe industrial emissions of radioactive materials into the atmosphere (Smirnov, 1992) and to contribute to the general geophysical system of earthquake prediction. It is well known that one of the precursors of earthquakes is the radon and hydrogen emanation in the regions of future epicenters (Vojtov and Dobrovol'skii, 1994; Liperovsky et al., 2008, 2011; Mikhailin et al., 2010; Ouzounov and Freund, 2004; Ouzounov et al., 2006). Such emanations may cause an intensification of IR emissions in the atmosphere. In this connection, the main problem is the construction of sufficiently sensitive spectral analysers to study IR spectra of intensive short-term processes in earthquake preparation regions. In the present work, the possibility of the diagnostics of regions of increased ionisation in the atmosphere before earthquakes using the method of infrared (IR) spectroscopy is discussed.

Earthquake lights were observed many times in the nights before strong, destructive earthquakes (Derr et al., 1973; Grigoriev et al., 1988; St.-Laurent et al., 2006; Fidani, 2010). But phenomena that can be clearly observed in the visible spectrum by the eyes only are rather rare. They were obtained for earthquakes with magnitudes $M>6$ only in 5 per cent of the cases (Papadoupolos, 1999). Satellite investigations of the equilibrium infrared radiation above Middle Asia, based on the analysis of daily registrations of the spectral interval of $10.5-11.3 \mu \mathrm{m}$ at night, first showed the existence of anomalies (Gorny et al., 1988). But to solve the problem of earthquake prediction, one has to study the modifications of infrared spectra of non-stationary emissions from discrete cloudy structures in the atmosphere. This is a rather difficult task.

Here it should be mentioned that recently infrared precursors were indeed found before the main disastrous earthquakes. GPS/TEC data observed before the $M=9$ Tohoku earthquake of 11 March 2011 indicate an increase and variation in electron density, reaching a maximum value on 8 March 2011. On 8 March 2011 also a rapid increase of emitted infrared radiation $(10-13 \mu \mathrm{m})$ was observed from satellite data measured at the top of the atmosphere integrating emissions from the ground, the near-surface atmosphere and clouds. An IR-anomaly developed near the epicenter 
(Ouzounov et al., 2012). Based on remote sensing images of FY-2C, thermal infrared anomalies were found to begin already 55 days before the $M_{\mathrm{s}}=8.0$ Wenchuan earthquake in Sichuan/China (Lejun et al., 2009). Thermal infrared anomalies were observed in correlation with the L'Aquila earthquake of 6 April 2009 (Lisi et al., 2010). Also in this case the anomalies, appearing between 30 March 2009 and 1 April 2009, were observed near the earthquake epicenter.

The model of the generation of quasi-homogeneous largescale anomalous electric fields in the near-Earth atmosphere before earthquakes by radon emanation was developed in the studies (Pulinets and Boyarchuk, 2004; Smirnov, 1992). But modifications of radon emanation by the deformation of granite rock cracks were already studied by Holub et al. in 1981 (Holub and Bready, 1981). Segovia et al. (1989) reported on the radon anomaly of a fault of the geothermal field "Los Azufres" prior to the destructive $\left(M_{\mathrm{S}}=8.1\right)$ Mexican earthquake of 19 September 1985. The geothermal field "Los Azufres" is situated about $260 \mathrm{~km} \mathrm{NE}$ of the later epicenter.

Another model of the electric process assumed the formation of non-stationary mosaic likely distributed Frenkel areas of the electric field in the atmosphere above earthquake preparation regions with characteristic length scales of hundreds of meters. These Frenkel areas are then sources of infrared emissions. The process is based on $\alpha$-particles with energies of $6 \mathrm{MeV}$, which occur during the radioactive decay of radon. Energy may be lost by repeated collisions with atmospheric molecules, cause an increase of the degree of ionisation of the atmosphere, and also excite molecules. So, the ionisation intensity of the atmosphere may rise by 1-3 orders of magnitude (Smirnov, 1992; Wick and Singh, 1994; Heinke et al., 1995; Pulinets and Boyarchuk, 2004). Further, the adsorption of water molecules to the molecular ions proceeds. As result, light (with less than nine attached $\mathrm{H}_{2} \mathrm{O}$ molecules), medium-weight, and heavy ions form. Then, the generation of charged aerosols starts. Their dimensions and densities grow at sufficiently high concentration of humidity. Finally, an electric field appears, which is about two-three orders of magnitude larger than the initial, background electric field of the atmosphere $\left(130 \mathrm{~V} \mathrm{~m}^{-1}\right)$, and it does not depend on the initial field. Estimates of the amplitudes of the appearing electric field are given in Liperovsky et al. (2005). A detailed analysis is presented in Liperovsky et al. (2010). If the pulses of the local electric field in the near-Earth atmosphere are not sufficiently strong for a breakdown during the earthquake preparation time, they may be, nevertheless, strong enough to excite the molecules of some rare atmospheric components and the corresponding IR emissions.

Let us discuss this point in more detail. In nature, the experimentally obtained and theoretically explained regularity exists, according to which the small-scale aerosols are mainly positively charged, and the large-scale aerosols possess a negative charge. Correspondingly, the larger aerosols move downward, relative to the small aerosols. The Frenkel charge separation by gravity works and electric fields are created. In the upper layers of the plasma cloud, the total charge is positive, and in the lower layers the cloud is negatively charged (Frenkel, 1949). In accordance with Liperovsky et al. (2008), the maximum amplitude of the pulse of the vertically directed, local electric field in the atmosphere satisfies $E_{\max } \sim V \rho_{+} /\left(S \varepsilon_{o}\right)$, where $\rho_{+}$is the volume density of the positive charge, $V$ designates the volume of the cloud of pancake form, $S$ is the cross section of the cloud, and $\varepsilon_{o}$ describes the dielectric constant of the vacuum. Thus $E_{\max }$ is determined by the ratio of the mean density of the positively charged particles to the unity of the projection of the cloud volume into the horizontal plane. The mosaic likely distributed in the atmosphere non-stationary regions with increased densities of rare atmospheric components, and Frenkel electric fields are sources of IR emissions, as the electrons that collect energy in the electric field deliver the energy for the excitation of the molecules and the associated energy emissions.

The experimental diagnostics of atmospheric disturbances observing the emission spectra at night and the absorption spectra at daytime is possible. In this connection, the observation of the rare atmospheric components is of large interest.

\section{The IR experiment at the Moscow State University}

At the Institute of Nuclear Physics of the Moscow State University, sources of IR emissions in the atmosphere are modelled in the laboratory in electric fields of $2 \times 10^{2}-10^{6} \mathrm{~V} \mathrm{~m}^{-1}$ to observe the corresponding IR spectra.

A scheme of the set-up of the experiment is presented in Fig. 1. The apparatus consists of a plasma-chemical reactor, a system for drying or increasing of humidity, the system of air cooling, and the device for the registration of the relative ozone concentration. The barrier discharge is used as plasmachemical reactor. To increase the efficiency of the synthesis, the reactor surface is cooled by a water system. The air delivery of $0.1 \mathrm{~m}^{3} \mathrm{~h}^{-1}$ is provided by the compressor (1). For the generation of ozone, an alternating voltage (5) with an amplitude of up to $25 \mathrm{kV}$ and a frequency of $13 \mathrm{kHz}$ is applied. The parameters of the electric pulse used to obtain ozone are given in Samoilovich et al. (1989).

The reactor (5) is disposed at the entry of cuvette (6) which is placed inside the optical spectrometer BRUKER IFS 66 V/8 (www.bruker-optics.de). Such a spectrometer allows for the measurement of emission and absorption spectra in the interval of wavelengths between 0.2 and $500 \mu \mathrm{m}$ (this corresponds to emitted or absorbed photon energies of $10^{-3}$ $6.25 \mathrm{eV}$ ). It is a FTIR (Fourier transform infrared) spectrometer based on Michelson interferometry (see e.g. Griffiths and De Haseth, 1986; Schrader, 1995) with a spectral resolution of $0.15 \mathrm{~cm}^{-1}$. For the instrument, various light sources, beam splitters including broad-band Mylar foils, 


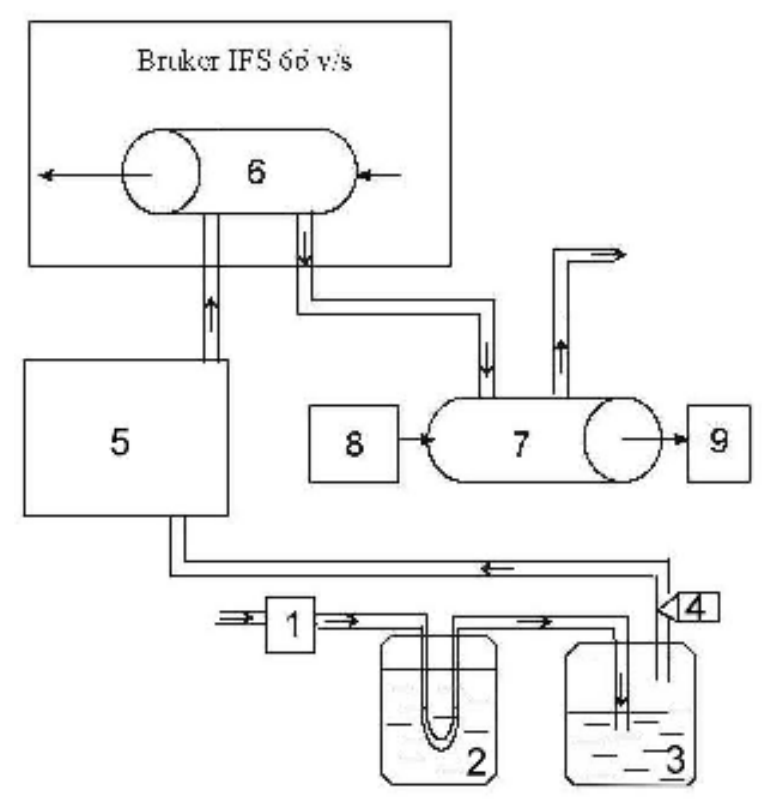

Fig. 1. Set-up of the IR experiment at the Moscow State University. 1 - compressor, 2 - cooling and drying system, 3 - system to increase the humidity, 4 - thermo-sensor, 5 - plasma-chemical reactor, 6 and 7 - cuvettes, 8 - lamp, 9 - photoreceiver.

and detectors including bolometers are available. Furthermore, beam condensers for micro-transmission, reflection with variable angle of incidence, attenuated reflection, and emission spectroscopy can be applied. Finally, polarizationand temperature-dependent measurements $(4-350 \mathrm{~K})$ can be carried out. The application of the BRUKER spectrometer at the Moscow State University is described in detail in Liperovsky et al. (2010).

The cuvette (6) consists of glass, but its windows are made from the crystal $\mathrm{BaF}_{2}$ with the transparency region 0.115$13 \mu \mathrm{m}$. The cuvette (7) is completely made from quartz. This cuvette is applied for the measurement of the ozone concentration using the absorption of the ultraviolet (UV) line at $254 \mu \mathrm{m}$, which is radiated by the lamp (8). The relative ozone concentration in the cuvette (7) is registered by the electric current in the photoreceiver (9).

Experiments were carried out at different humidity and air temperature. For these purposes the systems of cooling and drying (2) or increasing of humidity (3) were used. To dry the air feeded into the apparatus, a nitrogen trap is used as first step in the cooling block. Then the air enters a meandering flask which is submerged in a Dewar vessel with liquid nitrogen. To control the temperature, a thermo-sensor (4) is installed upstream of the reactor.

The working chamber (5) and the absorption unit (6) are filled with atmospheric air and one of the materials $\mathrm{O}_{2}, \mathrm{~N}_{2}$, $\mathrm{CO}_{2}, \mathrm{O}_{3}, \mathrm{CH}_{4}, \mathrm{~N}_{2} \mathrm{O}, \mathrm{NO}_{2}, \mathrm{CO}$, and $\mathrm{H}_{2} \mathrm{O}$. The registration of the current is possible in the working chamber. Dependent on the voltage, it is possible to obtain pulses of dependent discharges. The pulses are visually registered. It is taken into account that, because of the ionization by $\alpha$-particles, not only the compounds considered by Zujev (1980), but also other short-lived compounds of nitrogen and oxygen may occur.

\subsection{Increase of the rare atmospheric components $\mathrm{N}_{x} \mathrm{O}_{\mathrm{y}}$ and $\mathrm{O}_{3}$ as earthquake precursor}

Let us consider the possibility of the application of the absorption spectra of the small components of the daytime atmosphere for the earthquake prediction. With the chosen device it is possible to imitate the increase of the concentration of such rare atmospheric admixtures like $\mathrm{NO}, \mathrm{N}_{2} \mathrm{O}$, and $\mathrm{NO}_{2}$, which indeed occur before earthquakes because of the ionization by radon.

In the former research works it was suggested that radon causes only an ionization. Electrons occur and are accelerated in the electric field by the Frenkel mechanism, and the electrons further excite vibrational transitions and, consequently, an IR emission. Now, as another chemical mechanism in the atmosphere, the decay of the $\mathrm{O}_{2}$-molecule because of the $\alpha$-emission, the formation of ozone $\mathrm{O}_{3}$ is investigated. By the interaction of ozone with nitrogen, the nitrogen oxides $\mathrm{NO}, \mathrm{N}_{2} \mathrm{O}$ and $\mathrm{NO}_{2}$ are built.

To obtain first results in the laboratory, the synthesis of $\mathrm{O}_{3}, \mathrm{NO}, \mathrm{N}_{2} \mathrm{O}$ and $\mathrm{NO}_{2}$ was performed without the direct use of $\alpha$-particles. Instead of the radiation by radon, the barrier discharge was applied.

Ozone was registered by the wavelengths of $0.254 \mu \mathrm{m}$ and in the region of $9.6 \mu \mathrm{m}$. All the nitrogen oxides were investigated in the spectral region up to $13 \mu \mathrm{m}$. The control of the ozone density was performed using the wavelength at $0.254 \mu \mathrm{m}$.

With the chosen equipment, the absorption spectra of nitrogen oxides were studied during the interaction with ozone. Even by the chemistry of the interaction of ozone with the nitrogen of the air, the nitrogen oxides may essentially change their concentration and composition.

Because of the small emission intensity and the insufficient resolution of the spectrometer, the emission spectra could not be observed in the interval of wavelengths between $7 \mu \mathrm{m}$ and $13 \mu \mathrm{m}$, but an increase of the intensity of the absorption spectrum of $\mathrm{NO}_{2}$ by 200 percent was registered experimentally. Thus it was suggested to analyse the increase of the nitrogen concentration - as possible earthquake precursor - and to study the dynamics of the absorption spectra of nitrogen oxides.

Under real daytime conditions, the IR emission from the source should cross a region with larger density of nitrogen oxides. In case of Earth-based observations, as example of the source, one may consider the scattered in the Earth's atmosphere IR emission of the Sun. It has to be mentioned that the concentration of nitrogen oxides decreases in water vapour at room temperature because of the formation of 
acids, which has to be taken into account interpreting the laboratory experiment.

It is suggested that before earthquakes, under the condition of the electric field and at increased ionization by radon, single clouds with larger concentration of the small nonstationary compounds of the atmosphere $\mathrm{N}_{\mathrm{x}} \mathrm{O}_{\mathrm{x}}$ occur. Performing spectral measurements in the IR region, one should obtain information on the formation of an earthquake precursor.

Performing Earth-based observations, one has to use at least two spectral devices to localise the region in the atmosphere with the anomalous absorption.

\subsection{On emission spectra in the nighttime atmosphere}

Because of the always existing radon and the cosmic rays, in the atmosphere the ionization rate is not so large. At normal pressure near the Earth's surface, it amounts to $10 \mathrm{~cm}^{-3} \mathrm{~s}^{-1}$. If the electron energy $W_{\mathrm{e}}$ is smaller than $W_{\mathrm{o}}=0.45 \mathrm{eV}$, it adheres to oxygen during the interaction with it, and an $\mathrm{O}_{2}^{-}$molecule forms. In this process, of course, also a third particle takes part, a molecule. Under standard conditions, in the atmosphere at the Earth's surface, the electron collides, on the average, every $\tau=10^{-10} \mathrm{~s}$. The lifetime of an electron is about $\tau^{*}=10^{-7} \mathrm{~s}$. The collisions with the nitrogen atoms are, above all, elastic ones, if they do not adhere. The electrons collide many times with the molecules and gain kinetic energy from the external electric field. The electrons then excite the above-described rare atmospheric molecules, and clouds of increased ionization may form before earthquakes.

Seldom, because of the elastic collisions, also excited ions may occur, which emit a quantum of energy in the IR interval, particularly also in the interval of IR transparency of $7-15 \mu \mathrm{m}$, which amounts to energies of about $0.08-0.18 \mathrm{eV}$. Dependent on the strength of the electric field and the time between two effective collisions, part of the energy of the electric field is lost because of the excitation of vibrational energy levels of some molecules of the atmosphere.

Again it has to be mentioned that the discussed molecules are $\mathrm{NO}, \mathrm{CH}_{4}, \mathrm{CO}_{2}, \mathrm{NO}_{2}, \mathrm{NO}, \mathrm{N}_{2} \mathrm{O}$, and $\mathrm{O}_{3}$. The total mean free path of an electron until the adherence is, on the average, $\lambda^{*} \approx 2.5 \times 10^{3} \lambda_{\mathrm{e}}$, where $\lambda_{\mathrm{e}}$ describes the mean free path in the case of elastic collisions at normal conditions. An analysis showed that the total mean free path until the adherence $\lambda^{*}$ should be four orders larger, i.e. $\lambda^{*} \approx 10^{4} \lambda_{\mathrm{e}}$. For instance, the maximum energy of the electron in the nearsurface atmosphere at $E=3 \times 10^{5} \mathrm{~V} \mathrm{~m}^{-1}, \lambda_{e}=4.5 \times 10^{-7} \mathrm{~m}$ amounts to $W_{\max } \approx 0.7 \times 10^{2} E e \lambda_{\mathrm{e}} \approx 10 \mathrm{eV}$, where $e$ is the electron charge. Part of the energy of the electrons may be used to excite rotational and vibrational energy levels of the atmospheric molecules. The amount of this part may only be determined by experiments.

During the time of elastic collisions, the electrons gain energy in the electric field. But if the energy of the electrons is strong enough so that their collisions with some of the neutral particles of the atmosphere are inelastic, their energy again decreases, losing energy:

$\frac{\mathrm{d} W}{\mathrm{~d} \lambda}=-C W, \quad C=\frac{k q}{\lambda_{\mathrm{e}}}$

where $q$ represents the mean energy loss because of an inelastic collision. $k$ equals the ratio of the number of elastic electron collisions to the total number of electron collisions - that means it describes the occurrence frequency of the inelastic collisions along the mean free electron path $\lambda_{\mathrm{e}}$ where the vibrational-rotational energy levels of the atmospheric rare components are excited. Later, the excited molecules lose the energy as electromagnetic emissions. In case that the free electron is catched by adherence in presence of a third particle, there may be also an energy transfer to this third particle. Thus the derivative of the mean electron energy in the electric field is expressed by the relation

$\frac{\mathrm{d} W}{\mathrm{~d} \lambda}=\frac{B}{W}-C W$.

The maximum energy may be estimated by

$W_{\max }=\sqrt{\frac{B}{C}}$ with $B=\frac{e^{2} E^{2} \lambda_{\mathrm{e}}}{4}$.

\subsection{Estimations of the emission intensity at $7-15 \mu \mathrm{m}$ in the laboratory}

Now the intensity of the emission spectrum registered by the spectrometer in the interval of $7-15 \mu \mathrm{m}$ will be considered. While the mean ionisation velocity of the atmosphere is about $v_{o} \approx 10 \mathrm{~cm}^{-3} \mathrm{~s}^{-1}$, before earthquakes mean values are observed that are about 1.5-2 times larger (Vojtov and Dobrovol'skii, 1994). It is possible to assume that, directly in the clouds of ionisation, the temperature of ionisation may increase by two-three orders, so that one has $v^{*} \approx 10^{3}-3 \times 10^{4} \mathrm{~cm}^{-3} \mathrm{~s}^{-1}$.

Accepting some rough model approximations, one may estimate the number of energy quanta $\Delta N_{L}$ registered by the spectrometer using the formula

$\Delta N_{L}=V_{L} k_{L} \xi \beta \chi \nu^{*} \Delta t$,

where $\chi v^{*} \Delta t$ equals the number of quanta emitted during the time interval $\Delta t$ by the volume unit. $V_{L}$ describes the total volume emitting in the considered IR-region. $\chi$ designates the number of quanta generated by one electron. Energetic considerations result into $\chi=W_{\max } / W^{*} \approx 10^{2}$, where, according to Eq. (3), $W_{\max }$ is of the order of $20 \mathrm{eV}$. $W^{*}=0.2 \mathrm{eV}$ describes the effective excitation energy of a quantum in the infrared spectrum at $7-15 \mu \mathrm{m} . \chi$ depends on the pressure and the electric field. $\beta=0.5$ is the aperture coefficient of the entry lens of the spectrometer. As not the whole energy collected in the electric field by the electrons is 
spent for the excitation of vibrational-rotational energy levels of the molecules, but only part of it, the approximate coefficient $k_{l} \approx 0.3$ is introduced.

Here only the emission within a small solid angle $\xi=$ $r_{o}^{2} /\left(4 l^{2}\right) \approx 10^{-2}$ is considered. The radius $r_{o}$ of the entry spectrometer lens is about $3 \mathrm{~cm} . l$ designates the effective distance between the emitting atmospheric volume and the entry lens. Under the condition that in the laboratory device a spectral reflector is used, which allows an effective input of the emission from the working chamber in the spectrometer, a value of $\xi=0.5$ is possible. Dependent on the volume of the working chamber and the increase of the concentration of the rare components of the atmosphere $\mathrm{CO}_{2}, \mathrm{O}_{3}$, $\mathrm{CH}_{4}, \mathrm{~N}_{2} \mathrm{O}$, and $\mathrm{NO}_{2}$, the number of quanta of infrared emissions changes. In case of a chamber with a working volume of $10^{3}-3 \times 10^{4} \mathrm{~cm}^{3}$, the number of quanta considered during a laboratory experiment, which lasts $10^{3} \mathrm{~s}$, amounts to $10^{10}-10^{15}$. The minimum sensitivity of the device is twothree orders of magnitude smaller. In nature, especially in the Earth's atmosphere at altitudes of $10-15 \mathrm{~km}$, the number of quanta of IR emission registered by the spectrometer at night is two-three orders of magnitude larger than in the laboratory experiment.

\section{Conclusions}

1. In connection with the search for new atmospheric precursors of earthquakes under nighttime and daytime conditions, a real physical process is modelled in the laboratory. The concentration increase of rare atmospheric components is considered, which is caused by the growth of the radon concentration before earthquakes.

It was shown that the absorption density in the spectral interval of $10-13 \mu \mathrm{m}$ growths. Thus the increase of the IR absorption may be interpreted as earthquake precursor. The approach should work better at night than during daytime because of the stronger noise during daytime.

2. Related to earthquake precursors at night, emission spectra are also studied analytically. The excitation processes of molecules are analyzed. The theoretical analysis showed that locally, in electric fields below the breakdown ones, free electrons gain energy. Usually the electrons collide often with the molecules elastically. Seldom, the electrons also excite rotational-vibrational levels of rare atmospheric components. The molecules lose their energy in the interval of IR transparency at $7-15 \mu \mathrm{m}$.

The intensities of the emission spectra are estimated. It is found that in nature and in the laboratory the emission intensity is near the limit of the recent device sensitivity.
Thus, for observations of emission spectra, the resolution of the spectrometer has to be further increased.

3. A device is created for the syntheses and accumulation of nitrous oxides. Experiments to observe the IR-spectra of ozone and nitrous oxides during the syntheses and during the further evolution of these molecules are performed.

For the earthquake prediction, practically, the investigation of emission spectra is most important, but, during the laboratory experiments, the radiation of the excited molecules is shifted by a time interval which is larger than the duration of the barrier discharge and lasts until a noticeable, measurable heating of the chamber occurs. Thus the modification of the laboratory equipment to measure emission spectra is a special task. Besides, in this case, the working volume of the chamber has to be enlarged considerably.

Acknowledgements. The authors thank the two referees for constructive remarks.

Edited by: M. E. Contadakis

Reviewed by: P. F. Biagi and one anonymous referee

\section{References}

Derr, J. S.: Earthquake lights: A review of observations and present theories, Bull. Seismol. Soc. Am., 63, 2177-2187, 1973.

Fidani, C.: The earthquake lights (EQL) of the 6 April 2009 Aquila earthquake, in Central Italy, Nat. Hazards Earth Syst. Sci., 10, 967-978, doi:10.5194/nhess-10-967-2010, 2010.

Frenkel, Y. I.: Theory of atmospheric electricity phenomena, GITTL, Moscow-Leningrad, 1949.

Gorny, V. I., Sal'man, A. G., Tronin, A. A., and Shilin, B. V.: Infrared emission of the earth - indicator of seismic activity, Doklady Academii Nauk SSSR, 301, 67-69, 1988.

Griffiths, P. R. and De Haseth, J. A.: Fourier transform infrared spectrometry, John Wiley and Sons, New York, 1986.

Grigoriev, A. I., Gershenson, N. I., and Gokhberg, M. B.: On the nature of the luminosity of the atmosphere during earthquakes, Doklady Academii Nauk SSSR, 300, 1087-1090, 1988.

Heinke, J., Koch, H., and Martinelli, G.: $\mathrm{CO}_{2}$ and radon measurements in the Vostland (Germany) - a contribution to earthquake prediction research, Geophys. Res. Lett., 22, 749-774, 1995.

Holub, R. F. and Bready, B. T.: The effect of stress on radon emanation from rock, J. Geophys. Res., 86, 1776-1784, doi:10.1029/JB086iB03p01776, 1981.

Lejun, W., Jianfeng, G., Jianhua, L., Zhenquan, L., Haibing, L., and Hui, C.: Satellite thermal infrared earthquake precursor to the Wenchuan $M_{S} 8.0$ earthquake in Sichuan, China, and its analysis on geodynamics, Acta Geol. Sin., 83, 767-775, 2009.

Liperovsky, V. A., Meister, C.-V., Liperovskaya, E. V., Davidov, V. F., and Bogdanov, V. V.: On the possible influence of radon and aerosol injection on the atmosphere and ionosphere be- 
fore earthquakes, Nat. Hazards Earth Syst. Sci., 5, 783-789, doi:10.5194/nhess-5-783-2005, 2005.

Liperovsky, V. A., Meister, C.-V., Liperovskaya, E. V., and Bogdanov, V. V.: On the generation of electric field and infrared radiation in aerosol clouds due to radon emanation in the atmosphere before earthquakes, Nat. Hazards Earth Syst. Sci., 8, 1199-1205, doi:10.5194/nhess-8-1199-2008, 2008.

Liperovsky, V. A., Umarkhodjaev, P. M., Mikhailin, V. V., Bogdanov, V. V., Maltsev, S. A., Liperovskaya, E. V., Kaisin, A. V., and Leksina, E. G.: A method of searching for earthquake precursors based on remote sensing of local electric fields in the atmosphere, Seismic Inst., 64, 272-278, 2010 (Engl. transl.).

Liperovsky, V. A., Meister, C.-V., Mikhailin, V. V., Bogdanov, V. V., Umarkhodgaev, P. M., and Liperovskaya, E. V.: Electric field and infrared radiation in the troposphere before earthquakes, Nat. Hazards Earth Syst. Sci., 11, 3125-3133, doi:10.5194/nhess-113125-2011, 2011.

Lisi, M., Filizzola, C., Genzano, N., Grimaldi, C. S. L., Lacava, T., Marchese, F., Mazzeo, G., Pergola, N., and Tramutoli, V.: A study on the Abruzzo 6 April 2009 earthquake by applying the RST approach to 15 years of AVHRR TIR observations, Nat. Hazards Earth Syst. Sci., 10, 395-406, doi:10.5194/nhess-10395-2010, 2010.

Mikhailin, V. V., Liperovsky, V. A., Silina, A. S., Bogdanov, V. V., Meister, C.-V., and Liperovskaya, E. V.: Generation of electric field and infrared radiation in the troposphere before earthquakes, Collection of Reports of the 4th Int. Conf. on "Solar-Terrestrial Relations and Percursors of Earthquakes", Paratunka/Kamchatka, 14-17 August 2007, edited by: Shevtsov, B. M. and Bogdanov, V. V., IKIR FEB RAS, PetropavlovskKamchatsky, 402-406, 2010.

Ouzounov, D. and Freund, F.: Mid-infrared emission prior to strong earthquakes analyzed by remote sensing data, Adv. Space Res., 33, 268-273, 2004.

Ouzounov, D., Bryant, N., Logan, T., Pulinets, S., and Taylor, P.: Satellite thermal IR phenomena associated with some of the major earthquakes in 1999-2003, Phys. Chem. Earth, 31, 154-163, 2006.
Ouzounov, D., Pulinets, S., Romanov, A., Romanov, A., Tsybulya, K., Davidenko, D., Kafatos, M., and Taylor, P.: Atmosphereionosphere response to the M9 Tohoku earthquake revealed by joined satellite and ground observations, Preliminary results, arXiv, available at: 1105.2841-1.pdf-Tohoku_EQ_manuscript_ 3c_ARX, 19 October 2012.

Papadopoulos, G. A.: Luminous and fiery phenomena associated with earthquakes in the East Mediterranean, Atmospheric and ionospheric electromagnetic phenomena associated with earthquakes, edited by: Hayakawa, M., Terrapub, Tokyo, 559-575, 1999.

Pulinets, S. A. and Boyarchuk, K. A.: Ionospheric precursors of earthquakes, Springer, Berlin, Heidelberg, New York, 215 pp., 2004.

Samoilovich, V. G., Gibalov, V. I., and Kozlov, K. V.: Physical chemistry of ozone, Moscow State University Press, Moscow, 1989.

Schrader, B.: Infrared and Raman spectroscopy, VCH, Weinheim, 1995.

Segovia, N., De La Cruz-Reyna, S., Mena, M., Ramos, E., Monnin, M., and Seidel, J. L.: Radon in soil anomaly observed at Los Azufres geothermal field, Michoacan: a possible precursor of the 1985 Mexico earthquake (Ms=8.1), Nat. Hazards, 1, 319-329, 1989.

Smirnov, V. V.: Ionisation in the troposphere, Gidrometeoizdat, St. Petersburg, 1992.

St.-Laurent, F., Derr, J. S., and Freund, F. T.: Earthquake lights and the stress activation of positive hole charge carriers in rocks, Phys. Chem. Earth, 31, 305-312, 2006.

Vojtov, G. I. and Dobrovol'skii, I. P.: Chemical and carbon-isotop instabilities of flows of natural gases in seismo-active regions, Fizika Zemli, 3, 20-31, 1994.

Wick, H. S. and Singh, B.: Radon recording of Uttarkashi earthquake, Geophys. Res. Lett., 21, 737-740, 1994.

Zujev, V. E.: Propagation of visible and infrared waves in the atmosphere, Soviet Radio, Moscow, 1980. 